\title{
O turismo no Morro da Babilônia (RJ): do reflorestamento ao Ecoturismo
}

\author{
Tourism in Babilônia Hill (RJ, Brazil): from reforestation to \\ ecotourism
}

Thays Lima Gottgtroy de Carvalho

\begin{abstract}
RESUMO
O Morro da Babilônia, localizado no bairro do Leme, zona sul do Estado do Rio de Janeiro, abriga remanescentes da Mata Atlântica, bioma de excepcional biodiversidade e elevadas taxas de endemismo que foram submetidos aos efeitos de intensa exploração e pressão antrópica durante muitos anos. A partir da década de 80 , algumas iniciativas da comunidade local e do poder público foram responsáveis pela recuperação desta devastada vegetação, através da atividade de reflorestamento e a transformação do território em uma Unidade de Conservação, atualmente, Parque Natural Municipal da Paisagem Carioca. Este artigo apresenta as etapas do processo de reflorestamento desta região e a consequente implantação do ecoturismo no Morro da Babilônia, com o objetivo de mostrar como esta atividade pode manter a conservação do ambiente natural, beneficiar a população do local e incentivar a educação ambiental. Para isso, foi necessário realizar uma pesquisa de campo qualitativa, a partir de reuniões e entrevistas com os idealizadores do projeto, órgãos gestores da Unidade de Conservação e os moradores locais. Os resultados da pesquisa demonstraram que a atividade de ecoturismo implantada no morro da Babilônia ainda enfrenta alguns desafios para se manter. No entanto, mesmo com dificuldades, consegue gerar benefícios diretos e indiretos para a comunidade local e cumprir o seu principal objetivo de garantir a conservação do ambiente natural.
\end{abstract}

PALAVRAS-CHAVE: Morro da Babilônia; Ecoturismo; Reflorestamento 


\section{ABSTRACT}

The Babilonia Hill, situated in Leme, south zone of Rio de Janeiro city, keeps the remainings of the "Rain Forest", a biome of exceptional biodiversity and high rates of endeism, which had been under the effects of intense exploration and anthropic pressure for many years. Since the 80 s, some actions have been taken by the local population and the government in order to recover the devastated vegetation, to reforest it, and to change location status to "Protected Area." Nowadays it is known as The Natural Municipal Park of Carioca Landscape. This article presents the reforestation process steps in this area and, as a consequence, the implementation of Ecotourism in the Babilonia Hill, with the objective of showing how Ecotourism activity is able to keep local nature preserved, as it can offer benefits to the local population, and also how it motivates environmental education. To get this information, it was necessary to conduct a qualitative research with the projects managers, with people from government and with the local people, by meetings and interview arrangements. The results demonstrated that the activity of Ecotourism implemented in the Babilonia Hill is still facing some challenges, in order to keep itself going. However, even with difficulties, it is able to provide direct and indirect benefits to the local population and to honor its principal aim of keeping natural environment preserved.

KEYWORDS: Babilonia Hill; Ecotourism; Reforestation.

\section{Introdução}

O atual sistema capitalista hegemônico, no qual a maior parte do mundo está inserida, se consolidou, basicamente, após o advento da Revolução Industrial, no século XVIII. Devido as mazelas geradas pela exploração desmedida dos recursos naturais para atender às necessidades desse sistema perverso, estamos vivenciando um período de crises, onde a natureza já nos mostra sinais de que o atual sistema de produção não é sustentável a longo prazo, vide as catástrofes naturais ocorridas nos últimos anos e a escassez de recursos (SANTOS, 2008). Com isso, a sociedade contemporânea vem percebendo a necessidade de estar atenta às questões ambientais e da necessidade de mudanças de comportamento em relação ao meio ambiente.

Nos últimos anos percebemos o crescimento do número de visitas às áreas naturais, o que nos mostra que parte da população citadina está sequiosa em resgatar o contato com a natureza, nossa fonte de vida (RABINOVICI; NEIMAN, 2008). Assim, as áreas protegidas começam a ser vistas como locais de grande importância também para a recreação e o lazer. Afinal, a população da cidade necessita de espaços junto à natureza para relaxar, se divertir, ou seja, esquecer, mesmo que momentaneamente, da vida conturbada das grandes cidades (DIEGUES, 1996).

As modalidades de turismo em áreas naturais despontaram, portanto, no setor econômico do Brasil em meados da década de 80 , e, principalmente a prática do ecoturismo tem crescido em todas as regiões do país nas quais há belas paisagens naturais e onde as características culturais também são marcantes. A definição do ecoturismo prevê que os indivíduos possam entrar 
em contato com as áreas naturais garantindo a sua sustentabilidade econômica e ecológica, com a inclusão das populações locais que assumem a responsabilidade de cuidar dessas áreas (RABINOVICI; NEIMAN, 2008).

Devemos considerar, ainda, as dificuldades que o ecoturismo enfrenta no cerne de sua definição e prática, haja vista que o termo é muitas vezes confundido e mal utilizado. Para que o ecoturismo cumpra a sua verdadeira função, este deve ser compreendido como um fenômeno social, capaz de minimizar as desigualdades sociais, contribuir para a conservação da biodiversidade e incentivar a educação ambiental (IRVING, 2006).

Diante do exposto, este artigo apresentará as etapas do processo de reflorestamento do Morro da Babilônia, Leme, Rio de Janeiro (RJ) (Figura 1) e a consequente implantação do ecoturismo na região, revelando como se deu o envolvimento da comunidade local nesse contexto, suas características e os desdobramentos produzidos por essa atividade turística.

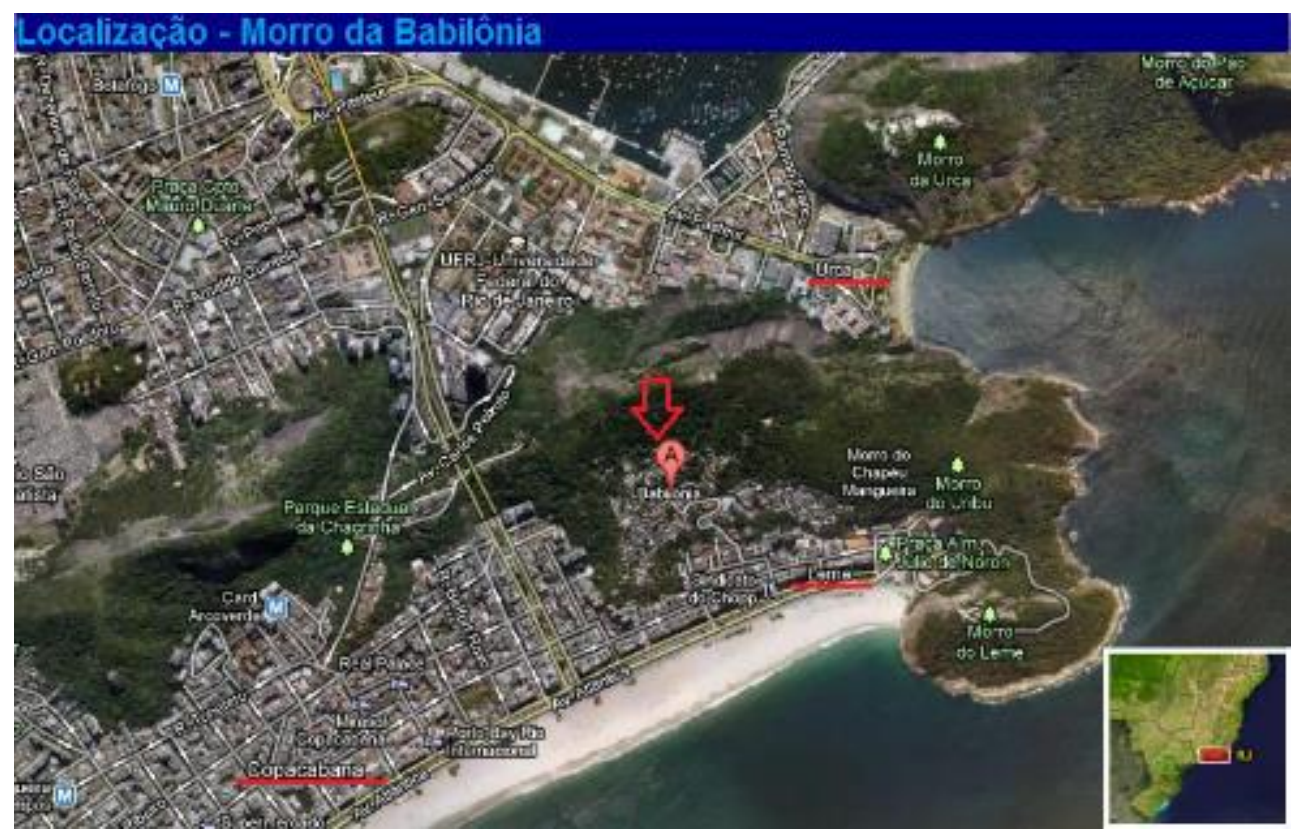

Figura 1: Localização do Morro da Babilônia, Leme, Rio de Janeiro. Indicações feitas pela autora. Figure 1: Babilônia Hill location, Leme, Rio de Janeiro, Brazil. Statements made by author.

Fonte: Google Maps.

Source: Google Maps.

\section{O Reflorestamento}

No final da década de 80, muitos moradores do Leme avistavam queimadas diárias no Morro da Babilônia e de São João. Após várias denúncias, a mobilização popular levou a Prefeitura do Rio de Janeiro a iniciar o reflorestamento ${ }^{1}$ do Morro da Babilônia e de outros morros da região, tendo a colaboração da Fundação Parques e Jardins (FPJ²).

Esse projeto acabou não tendo continuidade, pois os Agentes de Reflorestamento contratados para o trabalho naquela localidade não possuíam conhecimentos adequados da vegetação nativa. Os agentes introduziram no ambiente espécies invasoras como a Leucena (Leucaena leucocephala) descaracterizando a vegetação do local. 
Diante deste episódio, as associações de moradores dos morros da região junto com as entidades ambientais que visavam manter e ampliar o reflorestamento das áreas devastadas na região se uniram com o objetivo de arrecadar verba e dar continuidade ao projeto iniciado pelo governo. Toda esta conjuntura deu origem, em 1997, à Cooperativa de Trabalhadores em Reflorestamento e Prestação de Serviços da Babilônia Ltda (CoopBabilônia).

A CoopBabilônia é formada por membros da comunidade local que atuaram e continuam atuando na recuperação ambiental do Morro da Babilônia, que apresenta a maior parte de sua cobertura vegetal recuperada após 16 anos de trabalhos em reflorestamento.

Em 1996, o prefeito da cidade do Rio de Janeiro na época, César Maia, reconheceu o resultado do trabalho da população e após muitas mobilizações populares, decretou a área reflorestada do morro da Babilônia e do morro São João, situados nos bairros da Urca, Leme, Copacabana e Botafogo, como Áreas de Proteção Ambiental (APA), cerca de 126ha (cento e vinte e seis hectares).

Em 2000, foi oficializado o Conselho Gestor das APAs (CGA), fundado por Nei de Mello Rivello, na Gerência da Gestão de Unidades de Conservação (GUC), da Secretaria Municipal de Meio Ambiente (SMAC), com caráter exclusivamente consultivo e com as seguintes atribuições:

participar na elaboração, avaliação, execução e divulgação de projetos relativos às APAs (art. $4^{\circ}, \mathrm{l}$ ); realizar atividades de mobilização da população e apoio a conservação, proteção e fiscalização ambiental (art. $4^{\circ}$, II) e p articipar na identificação de parcerias de recursos para implantação de projetos (art. $4^{\circ}$, III). $\mathrm{O}$ Conselho Gestor elaborará e publicará relatório anual sobre suas atividades (art. 9º) (COOPBABILÔNIA, 2009. p.7).

Com isso, desde 2001, os trabalhos de recuperação ambiental nos Morros da Babilônia, Leme, Urubu, São João Batista e Cabritos passaram a ser realizados integralmente pela Cooperativa de Trabalhadores em Reflorestamento e Prestação de Serviços da Babilônia, em parceria com o Condomínio do Edifício Rio Sul Center e a Prefeitura Municipal do Rio de Janeiro, tendo como mão-de-obra os trabalhadores da própria comunidade (ZERBINATO, 2013) ${ }^{3}$.

Essa parceria com o Shopping Rio Sul, se deu em função da construção irregular do quarto piso do prédio do shopping (garagem), que ultrapassou os limites previstos em lei, por estar próximo a uma Área de Proteção Ambiental. Essa obra rendeu ao shopping uma multa alta, mas este recorreu e através do TAC - Termo de Ajustamento de Conduta Ambiental foi acordado entre as partes que o shopping subsidiaria um projeto sem fins lucrativos durante 4 anos. Nesse contexto, a CoopBabilônia foi escolhida para receber o patrocínio do shopping. A parceria deu certo e até hoje o Rio Sul é responsável pelo pagamento dos integrantes da CoopBabilônia. 
A cooperativa formada essencialmente por moradores do morro enfrentou muitas dificuldades para concluir o reflorestamento. $O$ trabalho exigia muito esforço físico, envolvendo atividades pesadas, como capinar, roçar e plantar mudas em uma área extensa. Mesmo com muitos problemas de falta de mão de obra e estrutura adequada para trabalhar, os moradores conseguiram vencer as adversidades e alcançar o sucesso. Hoje, a área reflorestada, livre de queimadas e desmatamento, possui cerca de 50ha (cinquenta hectares), com mais de $\mathbf{3 0 0}$ mil mudas plantadas.

Os resultados do reflorestamento são perceptíveis, de acordo com cálculo realizado no início de 2008, com uma redução de cerca de 6 toneladas de monóxido de carbono (CO) por ano que seriam despejados diretamente na atmosfera. Além disso, a iniciativa da prefeitura colaborou para 0 reflorestamento de outras áreas carentes da cidade do Rio de Janeiro, que através do Programa Mutirão Reflorestamento, em atividade desde 1987, promoveu o reflorestamento de encostas e de manguezais da cidade.

Esse programa inaugurou um componente inovador nos programas de reflorestamento urbano: a participação direta das comunidades carentes beneficiadas na realização dos plantios em regime de mutirão remunerado (SMAC, 2003).

Devido a tamanha importância e relevância ecológica do local, em junho de 2014, o prefeito Eduardo Paes, através do decreto de lei N. 37.231 , elevou a área à categoria de Parque Natural Municipal da Paisagem Carioca. Com essa alteração, o local passou a ser mais valorizado, facilitando, assim, a sua gestão, além de garantir a manutenção da conservação dos atributos ecológicos do local.

Segundo César Zerbinato, um dos implementadores do projeto, as mais de 300 mil mudas plantadas na região, somadas ao constante monitoramento e manejo de trilha, tornam o local um dos melhores trabalhos de reflorestamento e preservação ambiental do Rio de Janeiro e do Brasil, reconhecido internacionalmente (Figuras 2 e 3 ).

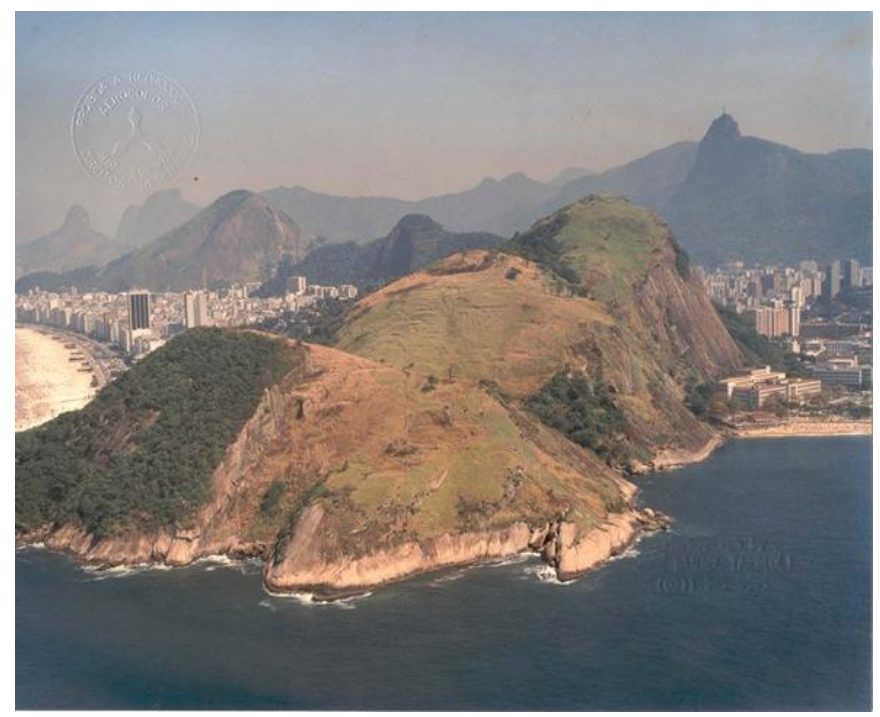

Figura 2: Morro da Babilônia e Morro São João antes do reflorestamento (1998).

Figure 2: "Babilônia Hill" and "São João Hill" before reforestation (1998).

Fonte: Cidade Inteira: http://cidadeinteira.blogspot.com.br/2010/09/memoria.html

Source: Cidade Inteira: http://cidadeinteira.blogspot.com.br/2010/09/memoria.html 


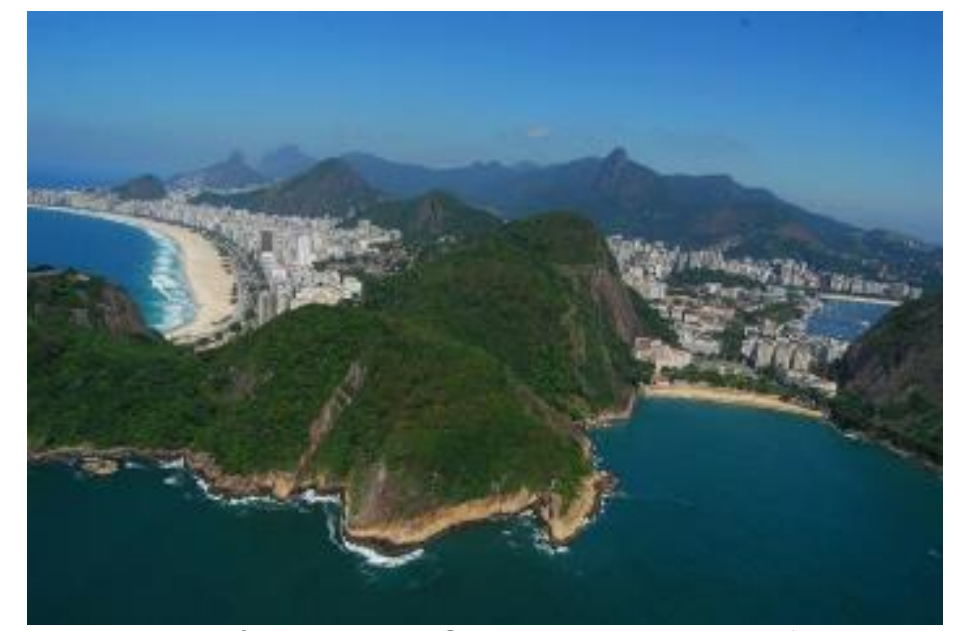

Figura 3: Morro da Babilônia e Morro São João depois do reflorestamento (2008). Figure 3: Babilônia Hill and São João Hill after reforestation (2008).

Fonte: Cidade Inteira: http://cidadeinteira.blogspot.com.br/2010/09/memoria.html

Source: Cidade Inteira: http://cidadeinteira.blogspot.com.br/2010/09/memoria.html

\section{Projeto "Andando na Trilha": Um caminho para o Ecoturismo}

De acordo com Zerbinato (2013), com o sucesso do reflorestamento, em 2004, os integrantes da CoopBabilônia começaram a levar turistas para conhecer as trilhas do morro. Eles adequaram a trilha para passeio, aproveitando o potencial do local, com atrativos naturais e histórico-culturais. No mesmo ano, Rodrigo Gaburro Trevisol, engenheiro florestal, responsável pelas atividades da Fundação Parques e Jardins no morro, e Carlos Antônio Pereira (Palu), Presidente da CoopBabilônia, elaboraram juntos aos interessados da comunidade do local, o Projeto "Andando na Trilha", que tinha por objetivo oficializar os circuitos de ecoturismo do local, aproveitando as trilhas que foram utilizadas primariamente para o reflorestamento.

Desta forma, não só os moradores locais, como toda a população carioca poderia usufruir de mais um espaço de lazer, além de conhecer os resultados do projeto de reflorestamento e aproveitar a vista privilegiada do alto do morro.

Com a divulgação de filmes como "Orfeu Negro" (1959), "Tropa de Elite" (2007) e o documentário "Babilônia 2000", gravados no morro da Babilônia, o local ficou mais conhecido e foi atraindo cada vez mais turistas, os quais procuravam conhecer a cultura da comunidade, gerando maior preocupação e necessidade de organização para o controle do fluxo de visitantes.

A partir do aumento das visitas, a CoopBabilônia, com o apoio da Prefeitura e do shopping Rio Sul, oficializou os passeios turísticos na região, organizados pelos próprios moradores e guias de turismo treinados pela associação, com apoio da prefeitura do Rio de Janeiro (ZERBINATO, 2013).

Em 2007, a Secretaria Estadual de Turismo (Setur) abriu um edital com o objetivo de fomentar projetos nas comunidades cariocas. O projeto vencedor receberia um valor em dinheiro $(R \$ 50.000,00)$ para a sua execução. Assim, a CoopBabilônia se interessou em participar da seleção e com muita 
organização e determinação, conseguiu enviar o projeto "Andando na Trilha". Em 2008, o "Andando na Trilha" foi selecionado e com o valor recebido a CoopBabilônia pôde melhorar a estrutura das trilhas, com degraus apropriados, bem como a construção de guarda-corpos, limpeza e sinalização, além de aprimorar os circuitos de ecoturismo e o roteiro turístico do local. O projeto também formou Agentes de Turismo Ambiental, em parceria com a EMBRATUR, para a orientação de turistas brasileiros e estrangeiros.

O "Andando na trilha" é um projeto que se preocupa com os fundamentos do ecoturismo e com o desenvolvimento sustentável. Desta forma, os agentes ambientais da CoopBabilônia continuam trabalhando em prol da manutenção da floresta, assim como de toda a área do Parque (GABURRO, 2013). Carlos Antonio Pereira, nascido e criado na Babilônia, atual presidente da Cooperativa de Reflorestamento e um dos mobilizadores do projeto, diz que "Uma das grandes vantagens que o projeto tem é motivar os próprios moradores da comunidade a participar. O Andando na Trilha também teve a participação de um engenheiro florestal, de um professor de turismo e outro de história. Todos os outros participantes são da comunidade". Rodrigo Gaburro, engenheiro florestal que participa do projeto, acrescenta: "Os guias tiveram aulas ligadas ao reflorestamento, vegetação e fauna. Quanto mais eles entenderem o meio ambiente onde irão atuar, mais vão ajudar a preservar o lugar". Edson Vander, um dos guias formados pelo Projeto, conta sobre os benefícios obtidos através do exercício dessa nova atividade, ao mesmo tempo em que percebe a transformação positiva do local onde mora. "As oficinas de capacitação do projeto me deram a noção que eu não tinha sobre a história da comunidade, de como ela foi formada. É um projeto que visa gerar renda não só para os guias, mas para toda a comunidade". Toda essa conjuntura tem por objetivo promover os guias e sua comunidade a longo prazo, sustentavelmente. $\mathrm{O}$ aumento da autoestima da população local, frequentemente associada a estereótipos negativos, melhoria da qualidade de vida e a geração de renda dentro da comunidade são elementos que não podem deixar de ser destacados neste cenário.

Em relação à natureza em si, são inúmeros os benefícios gerados com as ações implantadas pelos projetos de reflorestamento e ecoturismo. Rodrigo Gaburro elucida que foram plantadas mais de 300 mil mudas de árvores nativas da Mata Atlântica. Os moradores afirmam que a fauna está retornando aos poucos a região, diversas espécies de mamíferos e principalmente aves que antes estavam sumidas já são identificadas pela comunidade. Não existem mais casos de deslizamentos de terra, tampouco de incêndio no morro. Os moradores destacam ainda que têm prazer e orgulho em morar numa área onde o verde e a natureza predominam.

Durante a pesquisa, tivemos a oportunidade de constatar alguns aspectos sustentáveis do projeto que merecem ser ressaltados, como por exemplo, a construção do "Telhado Verde", no início de 2010, no prédio da Escola Tia Percília. O Telhado Verde é, segundo Silva (2011) uma cobertura verde ou jardim suspenso feito com grama ou plantas e que pode ser instalado em lajes ou sobre telhados convencionais, proporcionando conforto térmico e acústico nos ambientes internos. 
Idealizado por duas turistas americanas que ficaram encantadas ao visitar a comunidade, o telhado verde foi implantado com o objetivo de captar e reaproveitar a água da chuva para abastecer o prédio da Escola que compartilha as instalações com a CoopBabilônia. A água da chuva é captada através de calhas e passa por uma tubulação até ser armazenada em uma cisterna. A água coletada é utilizada para lavar carros e manter a limpeza do prédio.

Outro Programa desenvolvido no morro da Babilônia pelos próprios moradores é o Programa de Educação Ambiental implantado na escola Tia Percília. O programa é realizado com as crianças da escola e foi desenvolvido há quatro anos por duas educadoras ambientais, ambas moradoras do morro - Patrícia Regina da Silva Ignácio e Kelly Cristina de Souza Correa. Esse trabalho começou após o sucesso do projeto de ecoturismo implantado pela CoopBabilônia. Patrícia Ignácio, sócia fundadora da Cooperativa e guia de ecoturismo, percebeu o interesse das crianças em participar de atividades lúdicas na floresta e passou a levar as crianças para o local. Essas atividades fizeram sucesso e com o apoio de outros professores, ela implantou o programa.

O projeto tem como objetivo estimular as crianças à reflexão dos seus hábitos cotidianos incentivando-as a adotar novos comportamentos capazes de minimizar os impactos negativos da ação humana ao meio ambiente (Figura 4). O trabalho consiste na apresentação de vídeos interativos sobre o meio ambiente, palestras educativas e atividades lúdicas, como a disposição adequada dos resíduos sólidos, a importância da reciclagem do lixo, a economia da água, entre outros.

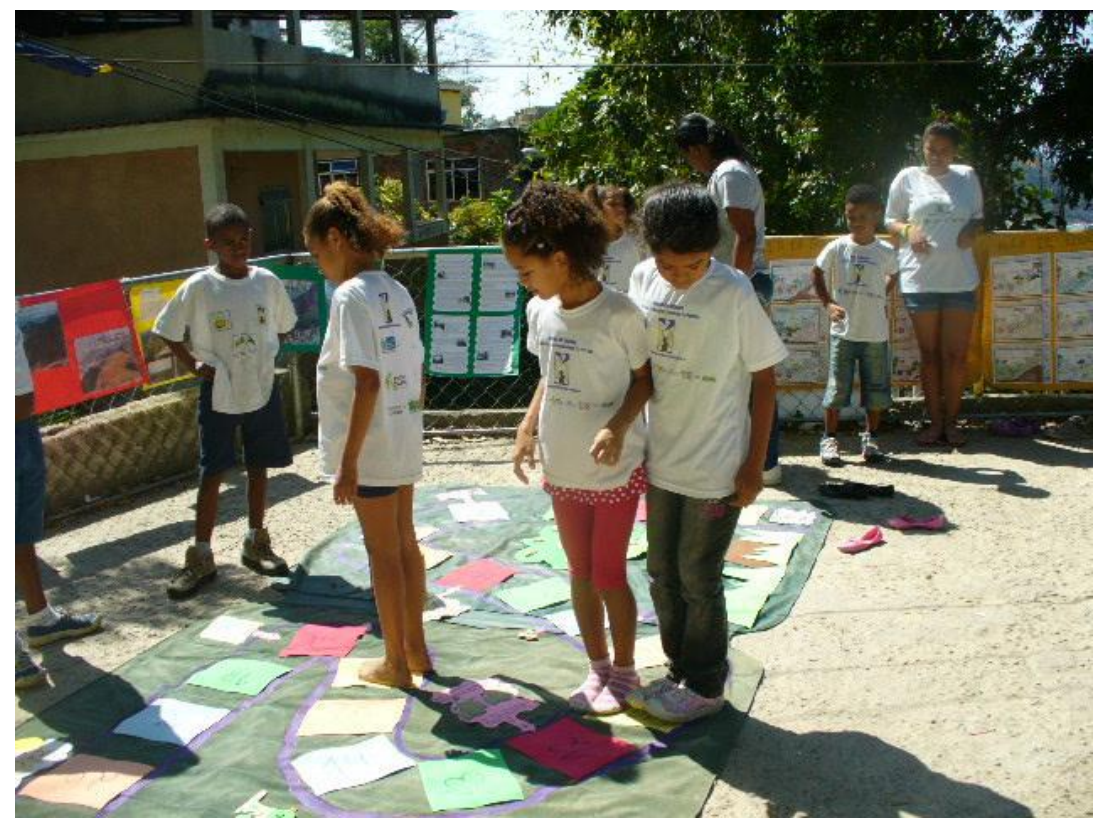

Figura 4: Crianças participam de atividades lúdicas do Programa de Educação Ambiental da Escola Tia Percília.

Figure 4: Children participate in recreational activities of the environmental Education Program of the School Aunt Percília.

Fonte: Arquivo de fotos CoopBabilônia.

Source: Photo Archive CoopBabilônia 
Além dessas atividades, as caminhadas pelas trilhas do Morro continuam fazendo parte do programa de EA. As educadoras levam as crianças da Escola Tia Percília e de outras escolas do bairro às áreas de reflorestamento para plantarem mudas, mostrando, dessa forma, a relação simbiótica entre a natureza e o ser humano. Através de iniciativas como essa, percebemos o despertar desses pequenos cidadãos para o respeito com o meio ambiente, bem como para a percepção da importância dessas mudanças comportamentais para o futuro do nosso planeta e, ainda, a disseminação desses novos aprendizados para suas casas.

Durante as aulas de E.A, outra atividade interessante do programa foi a construção de uma pequena horta feita pelos alunos. Eles utilizaram garrafas pets como vasos para a plantação de mudas de hortelã, cheiro verde, salsa, cuentro, couve, cebolinha, capim-limão, entre outras.

\section{Os atrativos do Morro da Babilônia}

$\mathrm{O}$ passeio pelas trilhas da Babilônia tem um diferencial. $\mathrm{O}$ visitante inicia a caminhada pela comunidade antes de chegar à área verde que faz parte do Parque Municipal e aqueles que não estão acostumados a adentrar territórios mistificados ficam apreensivos por ser um local mais conhecido pelas suas mazelas, mas, assim que eles começam a subir a ladeira Ary Barroso percebem um ambiente contrário ao que o nosso imaginário reproduz previamente. O local é tranquilo, calmo e os moradores cumprimentam os turistas sem restrição.

Essa caminhada pode ser feita a pé (20 minutos) ou com a ajuda de uma moto-táxi ${ }^{4}$ (5 minutos). Depois da subida, chega-se à sede da CoopBabilônia, junto ao prédio temos a Escola Tia Percília e no mesmo terreno, logo em frente, temos o Centro Municipal de Saúde do Chapéu Mangueira e Babilônia, a Sala da Associação de Moradores da Babilônia AMB e a lojinha das Mulheres Guerreiras da Babilônia - MGB. Este ponto também é de interesse turístico, pois é, geralmente, o local onde os guias passam as instruções do passeio para os visitantes antes da subida até o cume do morro.

No caminho, os turistas aproveitam para fotografar a realidade das comunidades carentes do Rio de Janeiro. Os moradores não se incomodam, acenam positivamente para as fotos, mandam beijos, deixando o passeio ainda mais agradável e descontraído.

Ainda no início da caminhada, encontra-se o histórico barraco feito de pau-a-pique, único no morro, onde reside o seu Tonico há mais de 70 anos (Figura 5).

A região do Morro da Babilônia possui um rico Patrimônio Histórico, Cultural e Natural, com diversificada fauna e flora, o que constitui um dos grandes atrativos da região especialmente se tratando de um roteiro ecoturístico. Existem viveiros na localidade com espécies nativas da devastada Mata Atlântica, como por exemplo, espécies de Pau-Brasil, Jequitibá e o Guapuruvu. O turista que desejar vivenciar uma experiência enriquecedora poderá plantar mudas na região, as quais são cedidas pela cooperativa dos moradores e que auxiliam na manutenção da floresta. 


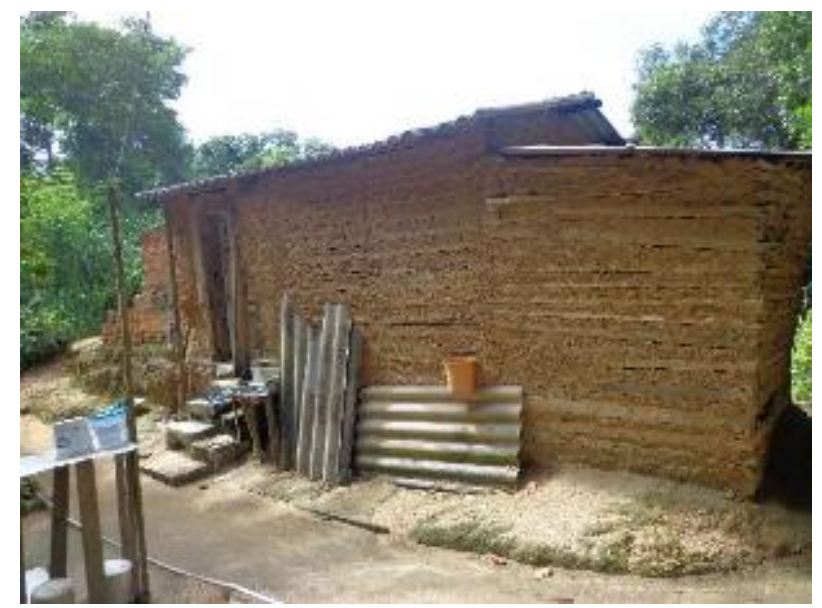

Figura 5: Barraco Histórico do Sr. Tonico - morador do morro da Babilônia há 74 anos.

Figure 5: Mr.Tonico's Historical House - He has been living there for 74 years.

Fonte: Carvalho (2013).

Source: Carvalho (2013).

Durante a caminhada, nos deparamos com vistas incríveis da cidade, além de algumas espécies da Mata Atlântica em extinção, como o PauBrasil.Todas identificadas pelos nomes populares e científicos, resultado do trabalho executado pela CoopBabilônia. As trilhas interpretativas são importantes para o ecoturismo, pois através da sua utilização percebe-se que há a valorização da atividade, expandindo a perspectiva do visitante para além da simples observação da natureza.

Após o reflorestamento, as aves típicas da Mata Atlântica retornaram ao seu habitat. Por exemplo, o Tucano de Bico Preto (Ramphastos vitellinus), muito comum em florestas fechadas, agora também habita o Parque Natural Municipal da Paisagem Carioca (Figura 6). O Tiê-sangue (Ramphocelus bresilius) é outra ave também encontrada neste Parque e exclusivamente no Brasil, com ocorrência em todo o litoral (Figura 7). Esta ave é comumente vista em florestas, restingas, plantações, parques e até em praças de cidades. Além dessas espécies, o parque abriga centenas de outras.

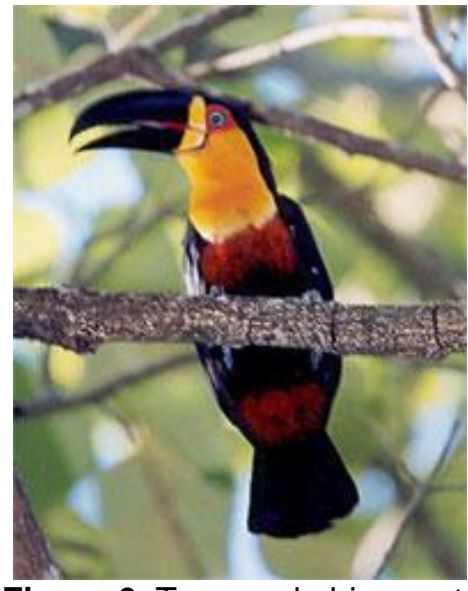

Figura 6: Tucano de bico preto (Ramphastos vitellinus).

Figure 6: Black Beak. Tucano. Fonte: Arquivo de Fotos da CoopBabilônia; Source Photo Archive CoopBabilônia;

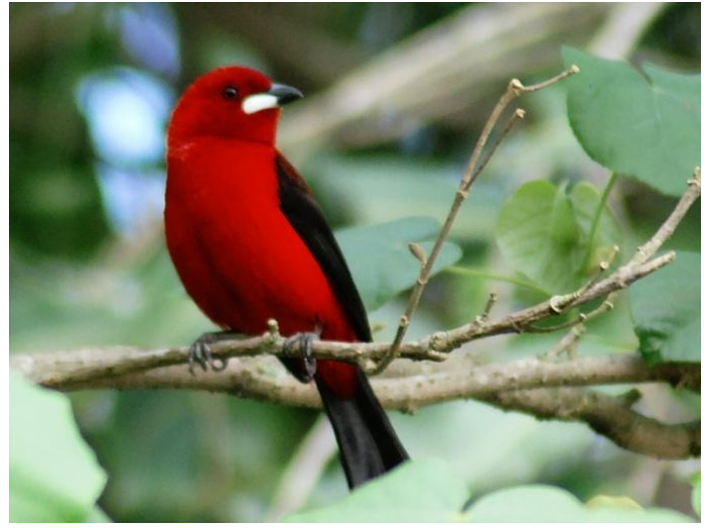

Figura 7: Tiê-sangue (Ramphocelus bresilius).

Figure 7: Blood Bird.

Fonte: Google Images.

Source: Google Images. 
O patrimônio histórico-cultural do local é constituído por construções que datam da época do Brasil colonial. O acervo conta com os fortes construídos para a defesa do litoral do Rio de Janeiro contra os corsários franceses, passando por casamatas construídas pelos militares durante a Segunda Guerra Mundial, utilizadas como ponto estratégico de observação da Baía de Guanabara, esconderijos, além de armazenar alimentos, armas e munição, segundo informações fornecidas pelos moradores do local.

Vale destacar ainda a permanência das famosas ruínas de uma casa construída por uma família portuguesa no alto do morro desde a época do Brasil-Colônia. Os pisos da casa e muitos de seus materiais foram trazidos da Europa, por isso, após o seu abandono, o local serviu de palco para gravações de filmes e documentários. Atualmente, é um dos pontos de interesse turístico, com uma bela vista para a praia de Copacabana.

As manifestações culturais promovidas pelos moradores do Morro da Babilônia, como o famoso "samba na laje", também fazem parte dos atrativos da região.

Contudo, a principal atração do Morro é ao final do passeio quando se chega ao seu cume e recebemos como presente uma vista espetacular de 360 graus da cidade do Rio de Janeiro. O visual apresenta o Corcovado, o Cristo Redentor, a Enseada de Botafogo, a Praia do Flamengo, Praia de Copacabana, a ponte Rio-Niterói, o bondinho do Pão de Açúcar e até partes de Teresópolis.

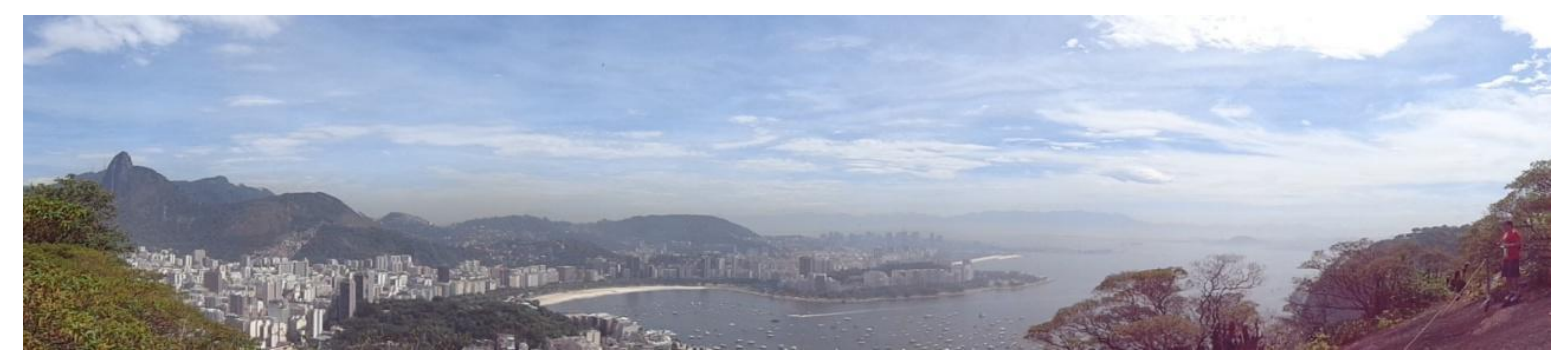

Figura 8: Vista panorâmica do alto do morro da Babilônia.

Figura 8: Panoramic view of Babilônia Hill.

Fonte: Carvalho (2013).

Source: Carvalho (2013).

\section{Os Desafios do projeto Andando na Trilha}

É notável que o projeto Andando na Trilha foi colocado em prática graças a muita força de vontade e determinação de grande parte da população do morro da Babilônia, como descrevemos até o momento neste trabalho. Todavia, através desta pesquisa, podemos perceber alguns desafios que os moradores ainda enfrentam para manter o trabalho de ecoturismo na comunidade.

A falta de comunicação e articulação entre as empresas que vendem o tour no morro e a CoopBabilônia, geraram conflitos na região. Embora o desenvolvimento da atividade turística no Morro não dependesse 
exclusivamente dessa parceria, ela era muito importante para a continuidade da atividade no local.

Hoje em dia, esse quadro mudou devido a atitude e organização da própria Cooperativa que proibiu as empresas de realizarem o passeio no Parque sem contratar os serviços da CoopBabilônia e/ou fazer uma reserva de condutores locais antecipada. Com essa atitude, a relação com as empresas privadas avançou consideravelmente. Hoje, a Cooperativa possui várias empresas e hotéis cadastrados para fazerem o passeio com qualidade e segurança. "As empresas agora ligam para a Coop para marcar os seus passeios, contratam os nossos guias, o almoço na laje, o pessoal do artesanato, assim fica um passeio legal e lucrativo para todas as partes. Agora, os guias das empresas trabalham junto com os nossos, é uma relação ótima" - aponta César Zerbinato, idealizador do Projeto. César Zerbinato ainda acrescenta que por ser um Parque, um espaço público, não é obrigatória a contratação de um guia para realizar o passeio, é somente aconselhável porque existem vários caminhos e as pessoas podem se perder. Qualquer cidadão pode realizar o passeio até o cume do morro, basta avisar para a Coop por segurança, mas o que não podia mais acontecer era a exploração excessiva das empresas que cobravam um valor absurdo dos turistas (em média 150 dólares por pessoa), dizendo que estavam beneficiando a comunidade e na realidade não ajudavam ninguém.

Segundo Rodrigo Gaburro, Engenheiro Florestal responsável pelo controle e manutenção do projeto de reflorestamento, o projeto de ecoturismo no morro ainda está em fase de estruturação, haja vista o potencial enorme do local para esta atividade. Ele acredita que o ecoturismo irá beneficiar um número maior de pessoas a partir do momento que for melhor estruturado, com mais visitas programadas, envolvendo mais moradores, com uma participação maior de guias da comunidade e comercialização de maior diversidade de produtos, incrementando, assim, os retornos econômicos para a comunidade. Isso ainda não foi possível, devido à falta de mão de obra qualificada para trabalhar com o ecoturismo. A Cooperativa ainda carece de um profissional especializado para trabalhar somente neste setor, dando a devida atenção às necessidades do projeto.

Toda a conscientização e organização do local deverá se estender também para os visitantes, como limpeza e embelezamento das vias de acesso. Cidadania, investimento em educação e satisfação de se morar num lugar mais valorizado, também são benefícios indiretos do projeto para a população (GABURRO, 2013).

Rodrigo sugere ainda que para otimizar os serviços prestados pela CoopBabilônia e expandir o projeto de ecoturismo, as trilhas devem estar sempre bem cuidadas e sinalizadas para receber o visitante, a limpeza e a ordem na comunidade também são importantes e estão em processo de melhorias. Saber o perfil do visitante também é essencial para que se possa atender às suas expectativas durante a visitação. 
Outro desafio que o projeto enfrenta é a segurança. Embora alguns moradores afirmem que a comunidade é bem tranquila e que nunca tiveram problemas graves com a violência, as favelas da cidade do Rio de Janeiro sempre foram vistas como locais violentos, cenários de crimes e tráfico de drogas, intimidando a visitação do turista. Ainda que na Babilônia não tenham acontecido sérios problemas, algumas visitas na área do Parque já tiveram que ser canceladas em função da falta de segurança. Desde a instalação das UPPs, esta situação vem mudando. A sensação de segurança no morro é sem dúvida maior, porque os moradores não têm mais que conviver com os bandidos andando armados livremente pela favela. Eles manifestam isso contudo, em determinados dias ainda são aconselhados a não subir até a parte mais alta do morro.

\begin{abstract}
A segurança nunca atrapalhou o nosso trabalho porque mesmo antes de ter UPP a gente já fazia os passeios. Depois da UPP melhorou a sensação de segurança, mas os bandidos mesmo não foram embora. A UPP não é esse mar de rosas que parece não. Mas aqui é muito tranqüilo, sempre foi. A gente nunca teve problema nenhum de tiro, gente morta por causa da violência. A nossa comunidade é muito organizada e ordeira. Pra você ter uma idéia, os bandidos daqui estudaram comigo, só que alguns seguiram o caminho errado e estão aí até hoje. Eu não. Eu não quis essa vida. Eu vim para Coop (Nilson Assunção, 34 anos, trabalha há 16 anos na CoopBabilônia).
\end{abstract}

Durante as entrevistas realizadas com os moradores do morro que não fazem parte do projeto, identificamos mais desafios a serem enfrentados para o incremento do ecoturismo no morro. Eles disseram que o projeto de ecoturismo ainda é pouco divulgado pela CoopBabilônia. Para inverter essa situação, alguns moradores sugerem que o produto (ecoturismo) seja melhor estruturado para que tenha condições de ser amplamente divulgado. Alguns moradores propõem que a divulgação em hotéis e empresas de turismo receptivo seja maior para que o morro receba mais turistas.

De acordo com os idealizadores do projeto, a falta de ferramentas adequadas para aumentar a divulgação do "Andando na Trilha" também é um ponto fraco do projeto. Eles dizem que a Cooperativa não possui, por exemplo, um profissional especializado para elaborar um site e mantê-lo atualizado. Hoje, é uma das maiores dificuldades que eles enfrentam para divulgar o projeto. A cooperativa elaborou um Blog e panfletos para auxiliar na divulgação dos passeios, sendo que essas ferramentas além de insuficientes, precisam ser atualizadas periodicamente para mostrar as novidades e as ações realizadas pelo projeto e isso não acontece, prejudicando muito o crescimento do projeto de ecoturismo no morro.

A respeito da divulgação, Rodrigo opina que em primeiro lugar deveria haver uma conscientização da comunidade local, como um todo, partindo da Associação de Moradores, com a finalidade de definir a posição de cada um no processo de ecoturismo. "Lembrando que o ecoturismo está apenas começando! Não foi mais divulgado anteriormente de propósito. Primeiro 
queríamos preparar a área, com sinalização, áreas de proteção, acesso com segurança nas trilhas, áreas recuperadas e pessoas minimamente treinadas para guiar". Mas ele reconhece que diante do cenário atual a cooperativa precisa investir na contratação (mesmo que temporária) de pessoas capacitadas para aperfeiçoar os meios de divulgação do projeto.

Outro ponto a ser aprimorado é o monitoramento das trilhas. As atividades de monitoramento são grandes aliadas da gestão das UC's (Unidades de Conservação). No caso em estudo, o Parque Municipal Natural da Paisagem Carioca possui um programa de monitoramento incipiente que precisa ser aprimorado a fim de que este identifique os impactos negativos que a visitação pode causar a esses ambientes e, assim, evitá-los, controlálos e minimizá-los.

Segundo Boo (1995), as populações, principalmente urbanas, vem buscando mais contato com ambientes naturais, aumentando consideravelmente a demanda pelas áreas naturais protegidas ou Unidades de Conservação. Estas áreas, na maioria das vezes, apresentam recursos raros, geralmente frágeis e suscetíveis a perdas irrecuperáveis se não forem adequadamente manejados pelos órgãos responsáveis e, também, protegidos pelas próprias populações. Com efeito, para garantir o sucesso e perpetuidade da condição das UC é necessário conhecer os impactos que a visitação pode causar a esses ambientes. Para tanto, a implantação de um sistema de monitoramento e gestão dos impactos da visitação é uma excelente estratégia (BOO, 1995).

Esse sistema se faz importante, principalmente, para que o ecoturismo alcance todo o seu potencial de gerar mais empregos e benefícios econômicos, com o menor prejuízo ao meio ambiente. Adicionalmente, a implantação de um programa desse tipo não pode ser o único recurso de identificação dos problemas presentes nas trilhas e atrativos, é imprescindível a participação constante da população local nesse tipo de monitoramento. A verificação dos impactos deve ocorrer constantemente e as intervenções para sua mitigação devem ser implantadas o mais rapidamente possível.

No Parque Municipal, o monitoramento das trilhas do projeto acontece de forma incipiente, devido às dificuldades geradas pela extensão da região. Apesar disso, o monitoramento existe e é feito com regularidade. A vigilância constante da população já poupou a área de situações desagradáveis, como por exemplo, uma construtora que visava levantar um condomínio na área do Parque, por onde passam as trilhas do projeto. A população denunciou a construtora para a prefeitura e conseguiram embargar o projeto.

Porém, para complementar as ações de monitoramento, outras medidas devem ser implantadas, como: após a realização das visitas guiadas, deveria existir um questionário para identificar a opinião, as sugestões e o perfil dos turistas que visitam o morro. Esse tipo de informação é importantíssima para identificar os pontos fortes do projeto e os pontos que precisam ser aprimorados, a fim de auxiliar a gestão e o planejamento da atividade turística da UC.

Outro problema que foi detectado pela pesquisa é que o Parque Municipal Natural da Paisagem Carioca ainda não possui Plano de Manejo ${ }^{5}$, isto dificulta a fiscalização e o monitoramento das áreas de vegetação, por 
exemplo, e de todos os outros atrativos que precisam ser acompanhados em uma UC que permite visitação. O Plano de Manejo está para a Unidade de Conservação como a Constituição está para o país: através deste documento é que se planejam os destinos da Unidade. Desta forma, é imprescindível a elaboração do Plano de Manejo do Parque. Sem este plano, a Unidade de Conservação não cumpre sua função, permanecendo apenas no papel. Desde 2007, há um documento que registra que em até cinco anos esse plano de manejo ficará pronto, o que não ocorreu até o presente momento.

\section{Considerações Finais}

O meu trabalho é maravilhoso, eu trabalho para o bem da humanidade e do meio ambiente, este é o meu primeiro emprego e será o último, quero me aposentar aqui, fazendo o que eu gosto! (Nilson, 34 anos, guia de turismo do Morro da Babilônia)

O Turismo é um fenômeno mundial que eclodiu no século $X X$. As viagens se estabeleceram quase como condição sine qua non na vida do ser humano, seja por motivos de trabalho ou mesmo de lazer havendo uma intensa massificação do turismo. Essa nova tendência produziu elevados ganhos econômicos para as cidades turísticas, porém, concomitante a isso, gerou também prejuízos ao meio ambiente. Deste modo, uma nova forma de turismo despontou nesse cenário - o Turismo Alternativo. Esta nova proposta de turismo engloba diversas atividades que podem ser realizadas na natureza como, por exemplo, o Ecoturismo. Essa atividade é uma verdadeira válvula de escape do cotidiano massacrante das cidades na qual permite que o ser humano resgate o contato com a natureza, gerando momentos únicos de reconhecimento de si mesmo e de reflexão sobre a vida. Permite ainda a discussão e reflexão sobre questões como o meio-ambiente, sua conservação e preservação e, principalmente, promove a inclusão social de muitos que até então viviam à margem da sociedade.

Salientamos que a atual estrutura segregadora da Área Metropolitana do Rio de Janeiro se caracteriza pela tendência a um modelo dicotômico do tipo núcleo-periferia, onde a cidade dos ricos se contrapõe àquela dos pobres. Sendo assim, é perceptível a crescente estratificação social do espaço, fazendo com que algumas áreas privilegiadas habitadas pela população abastada da cidade sejam contempladas por políticas públicas eficazes que garantam condições dignas de habitação, serviços e estrutura física para a vida desses cidadãos. Enquanto outros locais menos valorizados pela indústria imobiliária, sofrem com a negligência do Estado até os dias atuais. Isso demonstra que os padrões de distribuição espacial das classes sociais no Rio foram e são altamente influenciados pela (não) ação do Estado.

Essas desigualdades, no que tange a provisão de serviços garantida pelo Estado, são uma constante na trajetória histórica da cidade carioca. Mais uma vez esse processo expulsara a baixa classe econômica da sociedade das áreas centrais e valorizadas da cidade e os mais humildes eram obrigados 
a construir moradias irregulares próximas aos locais de trabalho, originando novas formas de habitação - as favelas.

O Morro da Babilônia apresenta um tour diferenciado dos que existem atualmente nos roteiros turísticos das favelas do Rio. Além de conhecer uma comunidade carente, o turista tem a oportunidade de visitar um Parque Natural Municipal no coração da cidade. A CoopBabilônia não incentiva o tour pela comunidade, eles trabalham com esse tipo de passeio, mas, em especial, nos casos em que os turistas solicitam ou quando alguns visitantes chegam para fazer a caminhada na trilha, desistem e pedem a visitação na comunidade. $O$ objetivo da cooperativa é desenvolver cada vez mais o ecoturismo, para que as pessoas possam aproveitar a área de floresta do local e conhecer a importância do trabalho de reflorestamento em uma área protegida inserida em perímetro urbano. Ao contrário do que muitos autores preservacionistas radicais defendem, as UCs não precisam ser somente "ilhas" de preservação afastadas da presença humana, pelo contrário, as que estão próximas da cidade conseguem receber um número maior de visitantes fazendo com que boa parte destes, ao entrar em contato com a natureza percebam que é possível haver uma relação harmônica entre a conservação de ambientes naturais e a presença humana desde que esta visitação aconteça de forma controlada.

O ecoturismo enquanto um produto turístico, instrumento educativo e de inclusão social têm um grande potencial a ser explorado no morro da Babilônia, no entanto, ainda é parcialmente aproveitado. As trilhas do Parque Natural Municipal da Paisagem Carioca apresentam riquíssima biodiversidade, com singulares espécimes da flora e fauna da Mata Atlântica, entre elas o Pau-brasil, as Helicônias, o Tucano de Bico Preto, micos e jacupembas. Atualmente, a CoopBabilônia já realiza um trabalho de identificação e controle desses espécimes. No entanto, melhorias das trilhas interpretativas e sinalização do local são necessárias. Além disso, a implantação de um Programa de Monitoramento da Qualidade da Visitação na área do Parque seria de grande valor para a região, a fim de garantir a continuidade da atividade turística com qualidade no local. Isso poderia ser feito através de pesquisas de identificação do perfil dos visitantes a fim de atender as suas expectativas e necessidades.

A ampla divulgação dos projetos realizados pela cooperativa e 0 incentivo para que novos agentes participem desses trabalhos é de extrema relevância, só assim os projetos terão continuidade e beneficiarão um número maior de famílias fazendo com que o ecoturismo cumpra seu papel de inclusão social.

Desta forma, podemos concluir que o Projeto de Ecoturismo "Andando na Trilha", implantado no Morro da Babilônia gera muitos benefícios para a população do local. Nota-se que à medida que o projeto for crescendo e se desenvolvendo, este atingirá um número maior de pessoas, consequentemente beneficiando ainda outras partes da comunidade. Deste modo, o Parque como sendo uma área protegida, cumprirá verdadeiramente o seu papel na medida em que conseguir equilibrar a conservação da natureza, o bem-estar da população local e promover a educação ambiental. 
Diante dos resultados alcançados através desta pesquisa, foi possível comprovar a relevância da realização de atividades como essas, promotoras de benefícios diretos e indiretos para população envolvida. Desta forma, espera-se ter contribuído para o enriquecimento da literatura de turismo e áreas afins, pela multidisciplinaridade do seu conteúdo, sobretudo, no que tange a implantação de projetos bem-sucedidos de ecoturismo utilizados como instrumento educativo e de inclusão social.

\section{Referências Bibliográficas}

ABREU, M.A. O estudo geográfico da cidade no Brasil: Evolução e avaliação (Contribuição à história do pensamento geográfico brasileiro). In: CARLOS, A,F.A. (Org.). Os caminhos da reflexão sobre a cidade e o urbano. Edusp: São Paulo Ano: 1994. Volume: v, p. 199-322.

ANDERSON, P. Balanço do neoliberalismo. In: SADER, E.; GENTILI, P. (orgs.) Pósneoliberalismo: as políticas sociais e o Estado democrático. Rio de Janeiro: Paz e Terra, 1995, p. 09-23.

ASSIS, L.F. Turismo sustentável e globalização: impasse e perspectivas. Revista da Casa da Geografia de Sobral, Ceará, v. 4/5 . p. 131-142, 2002 / 2003. Disponível em: <http://www.uvanet.br/rcgs/index.php/RCGS/article/view/84/81>. Acesso em: 10 dez. 2014

BOO, E. O Planejamento Ecoturístico para Áreas Protegidas In: LINDBERG, K; HAWKINS, D. (Org.) Ecoturismo: um guia de planejamento e gestão. São Paulo: Editora Senac; 1995. p.31-40.

BRUHNS, H.T. A busca pela natureza: turismo e aventura. São Paulo: Manole, 2009.

DIAS, R. Introdução ao Turismo. São Paulo: Editora Atlas S.A., 2005.

DIEGUES, A.C. O mito moderno da natureza intocada (2 ${ }^{\mathbf{a}}$ Ed.). São Paulo: Hucitec, 1998.

FACO, R.A.; NEIMAN, Z. A Natureza do Ecoturismo: conceitos e segmentação. In: NEIMAN, Z.; RABINOVICI, A. (Orgs.). Turismo e meio ambiente no Brasil. Barueri: Manole, 2009.

FREIRE-MEDEIROS, B. Gringo na laje. Rio de Janeiro: FGV, 2009.

GEERDINK, S.; NEIMAN, Z. A Educação Ambiental pelo Turismo. In: NEIMAN, Z; RABINOVICI, A. (Orgs). Turismo e meio ambiente no Brasil. Barueri: Manole, 2009.

LAGES, V.N. Territórios em Movimento: cultura e identidade como estratégia de inserção competitiva. .1. ed. Brasília: Relume Dumará, 2004. p. 25-30.

LOUREIRO, C.F.B. e AZAZIEL, M. Áreas protegidas e inclusão social: Problematização do paradigma Analítico-linear e seu separatismo na gestão ambiental. In: Irving, M. de A. (org.). Áreas protegidas e inclusão social: construindo novos significados. Rio de Janeiro: Aquarius, 2006. p.116-126.

Ministério do Meio Ambiente. O Sistema Nacional de Unidades de Conservação da Natureza. Brasília: Ministério do Meio Ambiente, 2011.

SANTOS, I.E. Manual de métodos e técnicas de pesquisa Científica. 6.ed. Niterói, RJ: Ed. Impetus, 2009. 
SILVA, F. M.; SILVA, K.R.S. O Novo Modelo de Segurança Pública no Rio de Janeiro: Violação ou Garantia de Direitos Humanos nas Favelas Cariocas. Revista Brasiliense de Pós - Graduação em Ciências Sociais. Vol. 11. 2012. Disponível em: <http://seer.bce.unb.br/index.php/revistapos/article/view/8654>. Acesso em: 08 mar. 2014.

\section{Notas:}

1 O reflorestamento é, conceitualmente, "uma ação ambiental que visa repovoar áreas que tiveram a vegetação removida pelas forças da natureza (incêndios, por exemplo) ou ações humanas, como queimadas, exploração de madeira e expansão de áreas" (IEF, 2008).

2 Fundação Parques e Jardins, vinculada à Secretaria Municipal de Meio Ambiente em 1993, é responsável pela administração dos parques municipais urbanos, planejamento, paisagismo, arborização e alguns projetos da cidade do Rio de Janeiro (PREFEITURA DO RIO, 2008).

${ }^{3}$ Informações obtidas em entrevista com César Zerbinato, presidente da Associação de Moradores da Babilônia e responsável pela realização das atividades de ecoturismo no Morro da Babilônia, Rio de Janeiro, março de 2013.

${ }^{4}$ Uma moto-táxi é um tipo de transporte público individual na qual os passageiros têm ampla escolha de local de embarque ou desembarque, o que não acontece com as modalidades de transporte em massa. É semelhante ao táxi, porém utilizando uma motocicleta em vez de um carro.

5 A Lei N.9.985/2000 que estabelece o Sistema Nacional de Unidades de Conservação define o Plano de Manejo como um documento técnico mediante o qual, com fundamento nos objetivos gerais de uma Unidade de Conservação, se estabelece o seu zoneamento e as normas que devem presidir o uso da área e o manejo dos recursos naturais. A Lei garante que todas as Unidades de Conservação devem dispor de um Plano de Manejo que deve abranger a área da UC, sua zona de amortecimento e os corredores ecológicos, incluindo medidas com o fim de promover sua integração à vida econômica social das comunidades vizinhas (Art.27§, 1ํ).

Thays Lima Gottgtroy de Carvalho: Universidade Federal Rural do Rio de Janeiro, Nova Iguaçu, RJ, Brasil.

E-mail: thaysgestora24@gmail.com

Link para o currículo Lattes: http://lattes.cnpq.br/1480688307192377

Data de submissão: 26 de fevereiro de 2015

Data de recebimento de correções: 17 de fevereiro de 2016

Data do aceite: 17 de fevereiro de 2016

Avaliado anonimamente 